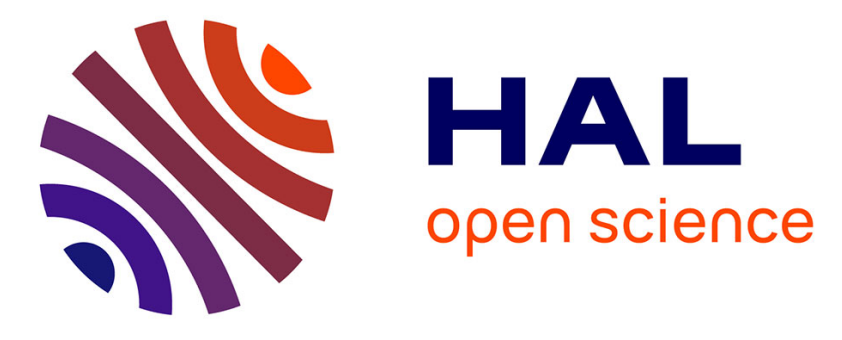

\title{
Low optical turn-on voltage in solution processed hybrid light emitting transistor
}

\author{
Abduleziz Ablat, Adrica Kyndiah, Alexandre Bachelet, Kazuo Takimiya, \\ Lionel Hirsch, Sophie Fasquel, Mamatimin Abbas
}

\section{- To cite this version:}

Abduleziz Ablat, Adrica Kyndiah, Alexandre Bachelet, Kazuo Takimiya, Lionel Hirsch, et al.. Low optical turn-on voltage in solution processed hybrid light emitting transistor. Applied Physics Letters, 2019, 115 (2), pp.023301. 10.1063/1.5090220 . hal-02181025

\section{HAL Id: hal-02181025 \\ https://hal.science/hal-02181025}

Submitted on 11 Jul 2019

HAL is a multi-disciplinary open access archive for the deposit and dissemination of scientific research documents, whether they are published or not. The documents may come from teaching and research institutions in France or abroad, or from public or private research centers.
L'archive ouverte pluridisciplinaire HAL, est destinée au dépôt et à la diffusion de documents scientifiques de niveau recherche, publiés ou non, émanant des établissements d'enseignement et de recherche français ou étrangers, des laboratoires publics ou privés. 


\section{Low optical turn-on voltage in solution processed hybrid light emitting transistor}

Cite as: Appl. Phys. Lett. 115, 023301 (2019); https://doi.org/10.1063/1.5090220

Submitted: 25 January 2019 . Accepted: 17 June 2019 . Published Online: 09 July 2019

Abduleziz Ablat, Adrica Kyndiah, Alexandre Bachelet, Kazuo Takimiya (D), Lionel Hirsch (D), Sophie Fasquel, and Mamatimin Abbas (iD)

\section{COLLECTIONS}

This paper was selected as Featured
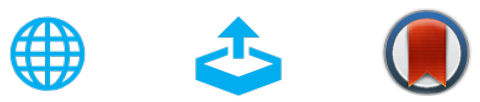

\section{rA AlluXa rouropical COATING PARTNER}




\title{
Low optical turn-on voltage in solution processed hybrid light emitting transistor $(5)$
}

\author{
Cite as: Appl. Phys. Lett. 115, 023301 (2019); doi: 10.1063/1.5090220 \\ Submitted: 25 January 2019 - Accepted: 17 June 2019 . \\ Published Online: 9 July 2019
}

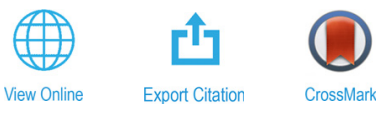

\begin{abstract}
Abduleziz Ablat,, ${ }^{1,2}$ Adrica Kyndiah,, Alexandre Bachelet, ${ }^{1}$ Kazuo Takimiya, ${ }^{3,4}$ (iD Lionel Hirsch, ${ }^{1}$ (D) Sophie Fasquel, and Mamatimin Abbas ${ }^{1, a)}$ iD
\end{abstract}

\author{
AFFILIATIONS \\ 'Univ. Bordeaux, IMS, CNRS UMR 5218, Bordeaux INP, ENSCBP, F-33405 Talence Cedex, France \\ ${ }^{2}$ School of Physical Science and Technology, Xinjiang University, 830046 Urumqi, People's Republic of China \\ ${ }^{3}$ Emergent Molecular Function Research Group, RIKEN Center for Emergent Matter Science (CEMS), 2-1 Hirosawa, $351-0198$ Wako, \\ Saitama, Japan \\ ${ }^{4}$ Department of Chemistry, Graduate School of Science, Tohoku University, 6-3 Aoba, Aramaki, 980-8578 Aoba-Ku, Sendai, Japan \\ ${ }^{a)}$ Email: mamatimin.abbas@ims-bordeaux.fr
}

\begin{abstract}
Low optical turn-on voltage is realized in a solution processed hybrid light emitting transistor (LET). To achieve that, an original approach has been applied where an emissive polymer is mixed with a hole transport small molecule. While the high mobility solution processed oxide determines the main electrical characteristics of the transistor as the electron transport layer, the hole transport molecule acts as an immediate source of positive charges to the emissive polymer within its matrix, thus resulting in more efficient light emission when the transistor is turned-on electrically. While the electrical turn-on voltage remains almost the same, the light turn-on voltage significantly decreases from $27 \mathrm{~V}$ in the control device to $2 \mathrm{~V}$ in the blend device. Furthermore, brightness and external quantum efficiency are also considerably improved within the whole range of gate bias in the blend device, evidencing that our approach enhances overall optical performance of a solution processed hybrid LET.
\end{abstract}

Published under license by AIP Publishing. https://doi.org/10.1063/1.5090220

Solution processed organic and oxide semiconductors have been attracting tremendous attention over the last decade for their potential applications in low cost, environmentally friendly, flexible, and large area electronics. Among various devices, light emitting transistors (LETs) belong to a special category as they combine both light emission and electrical switching in a single optoelectronic device, which can simplify active matrix display design and also are potential candidates for achieving electrically pumped lasers. ${ }^{1-4}$ Realizing efficient LETs is rather challenging from a single active layer, as strong electroluminescence and high carrier transport are mutually exclusive in general. ${ }^{5,6}$ Including transport and emissive layers in the stacking configuration is a viable path to achieve both high current density and strong light intensity. ${ }^{7,8}$ Such a multilayer approach can be easily implemented in vacuum deposited devices; nonetheless, it poses a serious challenge to solution processed devices as orthogonal solvents have to be considered for not destroying the already deposited underlayer. The first solution processed LET, the active layer of which is composed of a p-channel transport layer and an emissive polymer, was reported by Namdas et al. ${ }^{9}$ Low solubility of the transport layer in the solvent used for the emissive layer enabled fabrication of such a bilayer, thus resulting in a rather high external quantum efficiency (EQE) of $0.15 \%$ in spite of relatively low hole mobility $\left(\sim 10^{-2} \mathrm{~cm}^{2}\right.$ $\mathrm{V}^{-1} \mathrm{~s}^{-1}$ ). Solution processed oxides provide better alternatives for such transport layers as they show high charge carrier mobilities (typically above $\left.1 \mathrm{~cm}^{2} \mathrm{~V}^{-1} \mathrm{~s}^{-1}\right){ }^{10,11}$ Hybrid LET was reported first by Muhieddine et al. using solution processed zinc tin oxide as the transport layer. ${ }^{12}$ Following that, different inorganic active layers, such as CdS and multilayer oxides $\left(\mathrm{In}_{2} \mathrm{O}_{3} / \mathrm{ZnO}\right.$ or $\left.\operatorname{In}_{2} \mathrm{O}_{3} / \mathrm{Ga}_{2} \mathrm{O}_{3} / \mathrm{ZnO}\right)$, were also examined for hybrid LETs. ${ }^{13,14}$

One major issue in these types of hybrid LETs is the large difference between the electrical and optical turn-on voltages $\left(\mathrm{V}_{\text {on }}\right)$, as rather high current density is required for light emission. Consequently, these devices show characteristics of either low optical $\mathrm{V}_{\text {on }}$ with large negatively shifted electrical $\mathrm{V}_{\text {on }}$ or high optical $\mathrm{V}_{\text {on }}$ albeit with acceptable electrical characteristics. In this work, we integrated a hole transport molecule in an emissive polymer matrix (Super Yellow) in a hybrid LET. 2,7-dioctyl[1]benzothieno[3,2-b][1]benzothiophene $\left(\mathrm{C}_{8}\right.$-BTBT) was employed as the hole transport molecule 
for the following reasons: first, it has shown high hole mobility. ${ }^{15}$ Second, due to its wide band gap, it does not absorb the light emitted by the Super Yellow. ${ }^{16}$ Third, it has a suitable deep HOMO (highest occupied molecular orbital) level $(\sim 5.4 \mathrm{eV})$ for hole transfer from the molecule to the Super Yellow $(\sim 5.4) .{ }^{17,18}$ Finally, it can also act as an electron blocker due to its rather shallow LUMO (lowest unoccupied molecular orbital) level $(\sim 2.1 \mathrm{eV})$. Our approach allowed efficient recombination of the opposite charges provided to the emissive polymer, respectively, by the electron transport oxide layer and hole transport molecule, thus resulting in significantly reduced optical $\mathrm{V}_{\text {on }}$ compared to the control device.

Figure 1 shows the device structures used for hybrid LETs: (a) for the control device and (b) for the blend device (10\% Super Yellow in weight). This blend ratio is optimized so as to achieve the highest brightness and lowest optical turn-on voltage (see the supplementary material). Tungsten polyoxometalate (POM) [polyhedral representation of which is shown in Fig. 1(c)] as an interlayer for $\operatorname{In}_{2} \mathrm{O}_{3}$ is applied following our recent work on improving the overall electrical performance of single component $\operatorname{In}_{2} \mathrm{O}_{3}$ thin film transistor (TFT). ${ }^{19}$

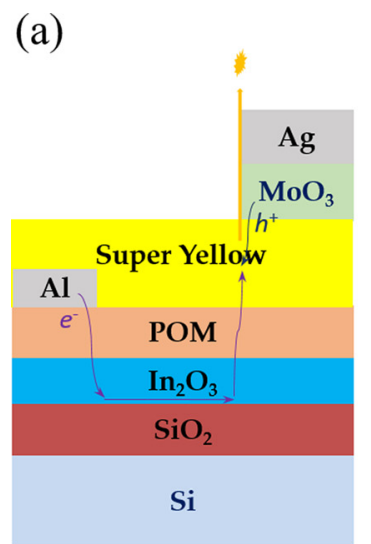

(c)
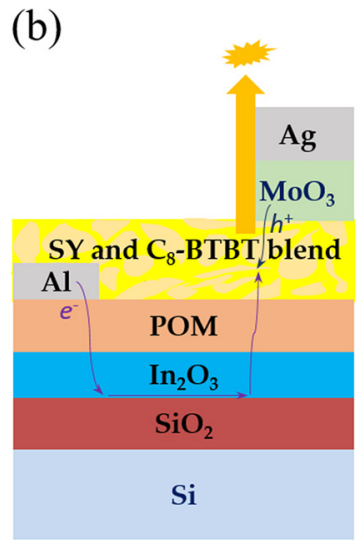

(d)
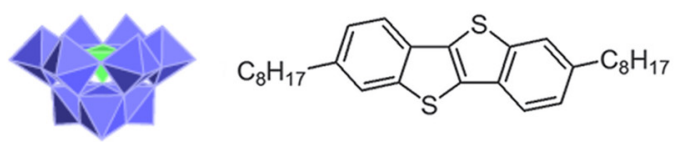

(e)

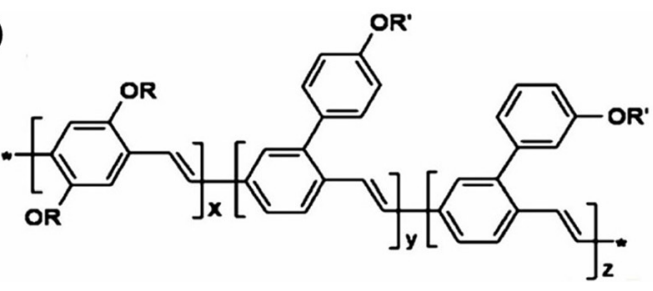

FIG. 1. Device structures of hybrid LETs: (a) control device and (b) blend device. Charge injection and transport paths, as well as light emission are also indicated. (c) Polyhedral representation of tungsten polyoxometalate $\alpha-\mathrm{K}_{9} \mathrm{PW}_{9} \mathrm{O}_{34} .16 \mathrm{H}_{2} \mathrm{O}$; the tetrahedral core represents $\mathrm{PO}_{4}$, while each of the nine octahedra represents $\mathrm{KWO}_{6}$. Chemical structures: (d) $\mathrm{C}_{8}-\mathrm{BTBT}$ and (e) Super Yellow.
Asymmetric source and drain contacts are used for efficient injection of both electrons and holes, respectively. ${ }^{20,21} \mathrm{MoO}_{3} / \mathrm{Ag}$ as the hole injection contact is chosen thanks to our recent investigations on various oxide/metal combinations as electrodes for the $\mathrm{C}_{8}$-BTBT hole transport molecule. ${ }^{22}$ Chemical structures of $\mathrm{C}_{8}$-BTBT and emissive polymer Super Yellow are shown in Figs. 1(d) and 1(e). Heavily doped silicon wafers $\left(15 \times 15 \mathrm{~mm}^{2}\right)$ with a thermally grown $\mathrm{SiO}_{2}(200 \mathrm{~nm})$ layer were used as substrates. The substrates were cleaned by ultrasonication in acetone, ethanol, and isopropanol followed by UV/ozone treatment for $10 \mathrm{~min}$. The $\mathrm{In}_{2} \mathrm{O}_{3}$ precursor solution was prepared by dissolving indium (III) nitride hydrate $(99.999 \%$ metal basis) in ethylene glycol monomethyl ether $\left(\mathrm{CH}_{3} \mathrm{OCH}_{2} \mathrm{CH}_{2} \mathrm{OH}, 99.5 \%\right)$ at a concentration of $30 \mathrm{mg} \mathrm{ml}^{-1}$. The solution was continuously stirred at room temperature for $24 \mathrm{~h}$ before use. The $\mathrm{In}_{2} \mathrm{O}_{3}$ thin films were deposited from the as-prepared precursor solution via spin coating at $4000 \mathrm{rpm}$ for $30 \mathrm{~s}$. After film deposition, the films were thermally annealed at $350^{\circ} \mathrm{C}$ for $1 \mathrm{~h}$. Both deposition and thermal-annealing processes were carried out under an ambient atmosphere. POM was dissolved in deionized water at a concentration of $1 \mathrm{mg} \mathrm{ml}^{-1}$ and then deposited by spin coating on the indium oxide layer. The samples were annealed on a hot plate at $125^{\circ} \mathrm{C}$ for $10 \mathrm{~min}$. Following that, the substrates were transferred to a nitrogen glovebox for electrode and organic active layer deposition. The masks were used to form asymmetric source and drain electrodes through evaporation. A $15 \mathrm{~nm}$ thick $\mathrm{Al}$ source electrode was directly deposited on top of the POM layer by e-beam evaporation. Then, either Super Yellow only solution or a mixed solution of Super Yellow and $\mathrm{C}_{8}$-BTBT (with ratio of 1:9) at a polymer concentration of $3 \mathrm{mg} \mathrm{ml}^{-1}$ in chlorobenzene (CB) was spin coated onto substrates at $3000 \mathrm{rpm}$ for $60 \mathrm{~s}$. The blend film is slightly thicker $(41 \mathrm{~nm})$ than the control film $(37 \mathrm{~nm})$ in average values. Then, the samples were annealed on a hot plate at $150^{\circ} \mathrm{C}$ for $20 \mathrm{~min}$. Finally, the $\mathrm{MoO}_{3} /$ Ag $(10 \mathrm{~nm} / 15 \mathrm{~nm})$ drain electrode was deposited by thermal evaporation on top of the Super Yellow and Super Yellow/C $\mathrm{C}_{8}$-BTBT blend thin films. For organic light emitting diode (OLED) devices, Poly(3,4ethylenedioxythiophene)-poly(styrenesulfonate) (PEDOT:PSS) (from CLEVIOS) of about $40 \mathrm{~nm}$ was deposited on precleaned ITO substrates. After drying the films at $120^{\circ} \mathrm{C}$ for $30 \mathrm{~min}$, the same active layers used for LETs were deposited by spin coating with exactly the same condition. $\mathrm{Ca} / \mathrm{Al}(20 \mathrm{~nm} / 60 \mathrm{~nm})$ electrodes were deposited by thermal evaporation.

Electrical and optical characterization of the devices were carried out using a Keithley 4200 semiconductor analyzer coupled with a calibrated silicon photodetector positioned over the devices in a dry nitrogen glovebox without exposure to air after the drain electrode deposition. The source-drain current and photocurrent from the silicon photodetector were recorded to determine the device parameters. The brightness of OLEDs was measured using a Konica Minolta luminance meter LS-100. The correction factor for photocurrent is thus established. The brightness of LETs was calculated from the photocurrent measured from the photodetector and corrected with the measured light emission area (at highest gate voltage) in the devices. The external quantum efficiency (EQE) was calculated using the gate voltage dependent brightness and source-drain current.

Both hybrid LETs with and without the $\mathrm{C}_{8}$-BTBT molecule exhibit remarkable electrical properties. Figure 2(a) shows the transfer characteristics of these devices in the saturation regime. Both devices show n-channel transistor behavior with small hysteresis and low 
(a)

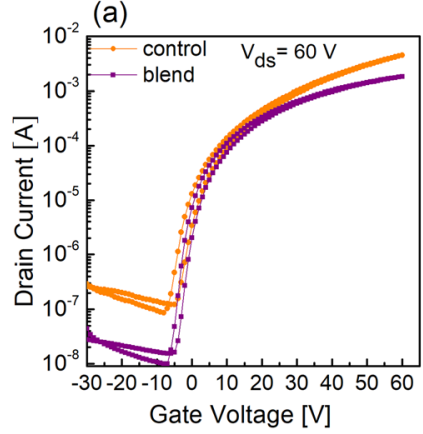

(c)

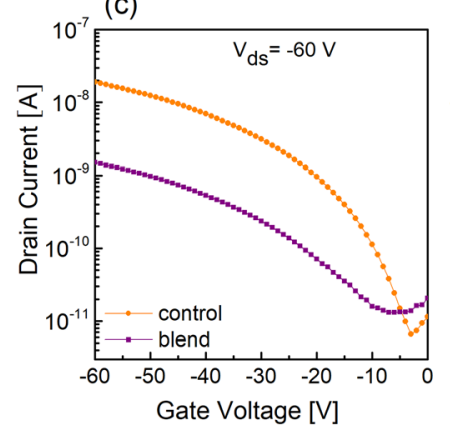

(b)

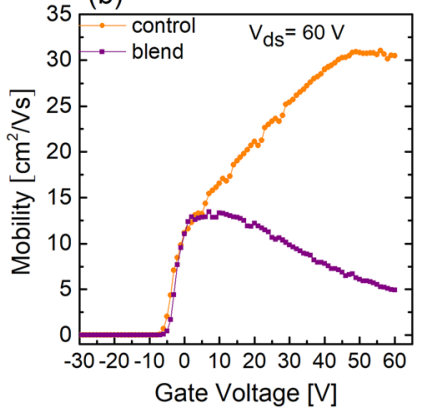

(d)

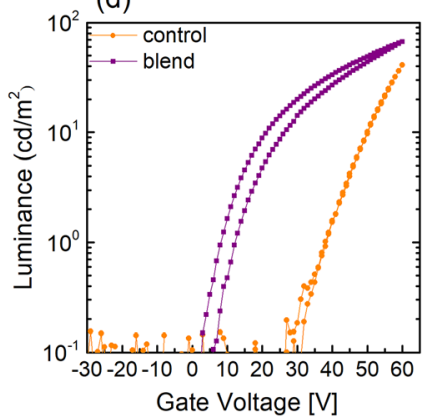

FIG. 2. (a) Transfer characteristics of control and blend hybrid LETs measured in the saturation regime. (b) Gate voltage dependent mobilities of the control and blend devices. (c) Transfer curves of both devices with hole injection electrodes. (d) Luminance of both devices as a function of gate voltage.

threshold voltage $\left(\mathrm{V}_{\text {th }}\right) . \mathrm{V}_{\text {th }}$ extracted using the standard method by the extrapolation of the square root of the drain currents is quite similar for both control and blend devices $(\sim 2$ and $3 \mathrm{~V})$. Both devices show low electrical turn on voltage $\left(\mathrm{V}_{\text {on }}\right)$ at about $-7 \mathrm{~V}$. The derived peak electron mobility of control and blend devices in the saturation regime obtained from gate voltage dependent mobility curve is $30.9 \mathrm{~cm}^{2} \mathrm{~V}^{-1} \mathrm{~s}^{-1}$ and $13.3 \mathrm{~cm}^{2} \mathrm{~V}^{-1} \mathrm{~s}^{-1}$, respectively, as shown in Fig. 2(b). The electron mobility of the control device is almost three times higher than that of the blend device, suggesting that the hole and electron recombination is strongly enhanced in the blend device. It is noteworthy that even the electron mobility of the blend device is one of the highest mobilities for single component oxide TFTs with operational $\mathrm{V}_{\text {th }}$ reported so far. ${ }^{11,23}$ The blend device shows slightly lower current density at $\mathrm{V}_{\mathrm{G}}=60 \mathrm{~V}$, owing to its lower mobility than the control device. However, the current on/off ratio of the blend device is still an order of magnitude higher than that of the control device (from $10^{4}$ to $10^{5}$ ), which comes from much lower off current in the blend device. Although the main electrical characteristics of our hybrid LETs are determined by $\mathrm{n}$-channel $\mathrm{In}_{2} \mathrm{O}_{3}$, hole current contributed by Super Yellow gives rise to the off current, as evidenced by the $\mathrm{p}$-channel performance of the Super Yellow only device as shown in Fig. 2(c). Surprisingly, when Super Yellow is mixed with $\mathrm{C}_{8}$-BTBT, $\mathrm{C}_{8}$-BTBT does not contribute to the hole current; instead, the hole current decreased almost an order of magnitude. The most striking difference of these two devices is observed in their optical properties. In Fig. 2(d), we present the luminance as a function of gate voltage for control and blend devices. The maximum brightness reaches $43 \mathrm{~cd} / \mathrm{m}^{2}$ in the

control device, while a higher brightness of $67 \mathrm{~cd} / \mathrm{m}^{2}$ is achieved in the blend device. As a matter of fact, the brightness of the blend device is significantly higher than that of the control device in the whole range of gate voltage modulation. Even more remarkable in this comparison is the light $\mathrm{V}_{\text {on }}$, which decreases from $27 \mathrm{~V}$ in the control device to only $2 \mathrm{~V}$ in the blend device, implying highly efficient electron and hole recombination in the blend device. Here, the role played by $\mathrm{C}_{8}$-BTBT is quite obvious. Holes can be easily injected from the $\mathrm{MoO}_{3} / \mathrm{Ag}$ contact to $\mathrm{C}_{8}$-BTBT, which in turn are immediately transported to Super Yellow in its vicinity. These trapped positive charges then recombine instantly with the electrons provided by the oxide transport layer, thus decreasing the optical $\mathrm{V}_{\text {on }}$. The summary and comparison of electrical, optical, and charge-transport properties of control and blend hybrid LETs are provided in Table I.

Indeed, atomic force microscopy (AFM) analysis (presented in Fig. 3) confirms that the blend film mainly processes polymer texture. Even with only $10 \%$ of content, Super Yellow still retains its percolation, albeit being slightly disturbed by the presence of the $\mathrm{C}_{8}$-BTBT molecule, which explains the lower off current we observed in the blend device. One might raise the question that AFM is only for the surface structure and $\mathrm{C}_{8}$-BTBT might form a layer underneath. In this scenario, hole current in the blend device would have been much higher than that in the super yellow only device, which is not the case as we noticed earlier in Fig. 2(c). It should be noted that even though $\mathrm{C}_{8}$-BTBT does not form a continuous layer to contribute to the hole current in the device, its high hole mobility is essential for fast transfer of positive charges from the electrode to the emissive polymer. We still observe the highly crystalline nature of $\mathrm{C}_{8}$-BTBT in the blend film as observed from the XRD measurement (see the supplementary material). Another important role it plays is acting as an electron blocker due to its much shallow LUMO level $(\sim 2.1 \mathrm{eV})$ as compared to that of Super Yellow $(\sim 3 \mathrm{eV}) .^{16}$

We present in Fig. 4(a) the microscopy images of the emitted lights together with the calculated external quantum efficiency (EQE) of both hybrid LETs. Emitted lights are clearly visible to the naked eye. We note that light emission in both devices happens mainly at the edge of the semitransparent $\mathrm{MoO}_{3} / \mathrm{Ag}$ electrode, which is understandable, as electrons are the dominant carriers in both devices. However, the light emission is much more spread under the electrode in the blend device, indicating again an efficient hole charge injection and transport. The EQE is calculated from the measured photocurrent and normalized electroluminescence (EL) spectrum. In the calculation, we also took into account the geometrical correction and light emitting

TABLE I. Summary and comparison of electrical, optical, and charge-transport properties of control and blend hybrid LETs.

\begin{tabular}{lcc}
\hline \hline & Control device & Blend device \\
\hline Threshold voltage (V) & $2.0 \pm 0.2$ & $3.5 \pm 0.4$ \\
Light turn on voltage (V) & $27 \pm 3$ & $2.0 \pm 0.2$ \\
Electrical turn on voltage (V) & $-7.7 \pm 0.5$ & $-6.6 \pm 0.8$ \\
Maximum brightness $\left(\mathrm{cd} \mathrm{m}^{-2}\right)$ & $41 \pm 8$ & $67 \pm 11$ \\
Maximum EQE (\%) & $0.02 \pm 0.006$ & $0.08 \pm 0.013$ \\
Current on/off ratio & $3.7 \times 10^{4}$ & $1.2 \times 10^{5}$ \\
Electron Mobility $\left(\mathrm{cm}^{2} \mathrm{~V}^{-1} \mathrm{~s}^{-1}\right)$ & $30.9 \pm 3.2$ & $13.3 \pm 1.2$ \\
\hline
\end{tabular}



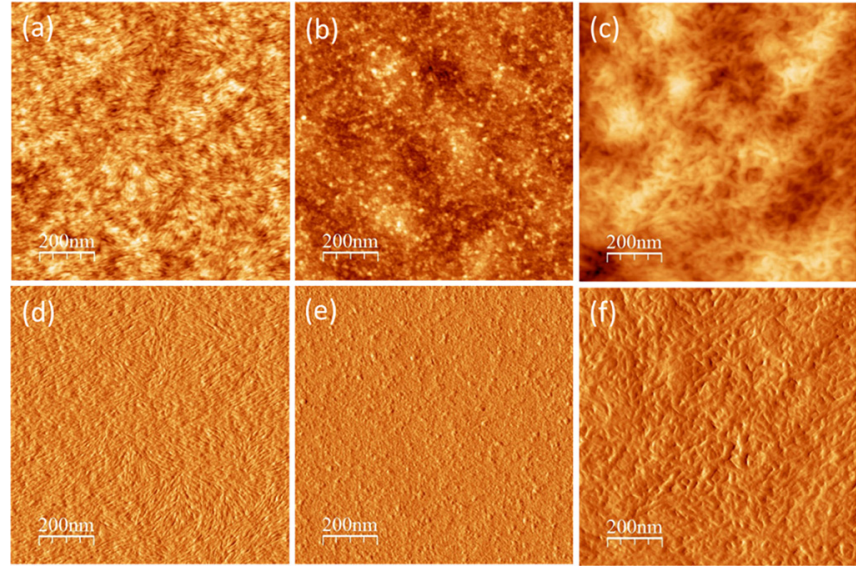

FIG. 3. AFM height and phase images of (a) and (d) Super Yellow, (b) and (e) $\mathrm{C}_{8}$ $\mathrm{BTBT}$, and (c) and (f) Blend films.

area of both LETs. In both devices, a gradual increase in EQE can be observed with the increase in the gate voltage, an indication of efficient electron injection from the $\mathrm{Al}$ electrode in our device configuration. Four times higher EQE (from $0.02 \%$ to $0.08 \%$ ) is achieved in the blend device as compared to the control device. Such an increase can be attributed to the role played by $\mathrm{C}_{8}$-BTBT in facilitating hole injection/ transport to the emissive polymer and also blocking the electrons, thus resulting in much more efficient charge recombination as discussed earlier. Electroluminescence spectra of the two devices together with photoluminescence spectra of the corresponding films with and without the $\mathrm{C}_{8}$-BTBT molecule are shown in Fig. 4(b). Photoluminescence of the blend film is almost the same as that of the Super Yellow only film. While electroluminescence of the blend device shows quite
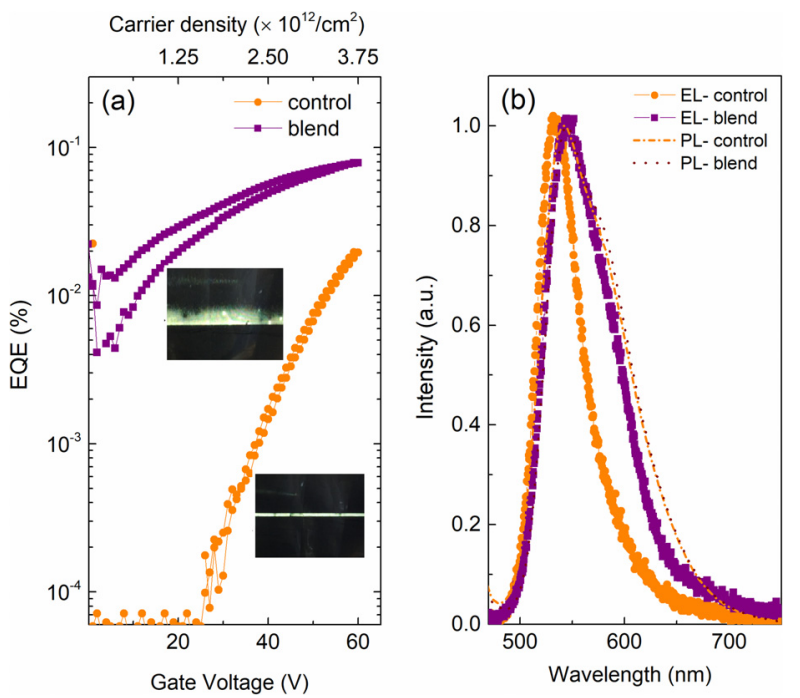

FIG. 4. (a) External quantum efficiency (EQE) of control and blend hybrid LETs, microscopy images of the emitted lights are also shown. (b) Photoluminescence spectra of control and blend films together with electroluminescence spectra of both hybrid LETs. similar features to the photoluminescence spectrum of the film, electroluminescence of the control device displays band narrowing and a slight shift in the peak, a hallmark of amplified emission coming most likely from rather confined emission. Still, the effect is not that prominent as the light emission is limited to the electrode edge, having surely been quenched by the electrode.

It is of relevance to fabricate equivalent light emitting diodes (OLEDs) and compare with hybrid LETs to highlight the role of the hole transport molecule in these two types of devices. We present in Figs. 5(a) and 5(b) the respective current density and brightness of the OLEDs with the active layer composed of control and blend films. Both current density and luminance are several orders of magnitude lower in the blend device compared to those in the the control device. Such an adverse effect of the hole transport molecule is expected in OLEDs, as the hole transport molecule perturbs the rather balanced electron and hole charge transport within the polymer, although a thin layer of $40 \mathrm{~nm}$ active layer does not require very high carrier mobilities. As determined from the space charge limited current (SCLS) measurement (see the supplementary material), hole mobilities decreased in the blend device, but electron mobility decreased much more, thus causing largely unbalanced charge transport of the opposite carriers, which is detrimental to charge recombination, consequently leading to a very poor OLED performance in the blend device. On the other hand, in our LETs, electrons have to travel much longer distances (on the order of tens of micrometers), which necessitates the integration of high carrier mobility transport layer in the device configuration. We also notice that electroluminescence band narrowing which we observed in LETs occurs neither in control (even with several orders of magnitude higher luminance) nor in the blend OLED device as shown in Fig. 5(c), suggesting that LETs can indeed be candidates for realizing electrically pumped lasers with further progress in device performance.

In summary, by blending the hole transport molecule with emissive polymer, we achieved a low optical $\mathrm{V}_{\text {on }}$ of only $2 \mathrm{~V}$ in a hybrid light emitting transistor. Our approach also led to the improvement of other optical properties such as brightness and external quantum efficiency. Although organic field effect transistor (OFET) and AFM studies show that the hole transport molecule does not tend to form a continuous percolation path, high crystallinity from XRD measurements suggests that the hole
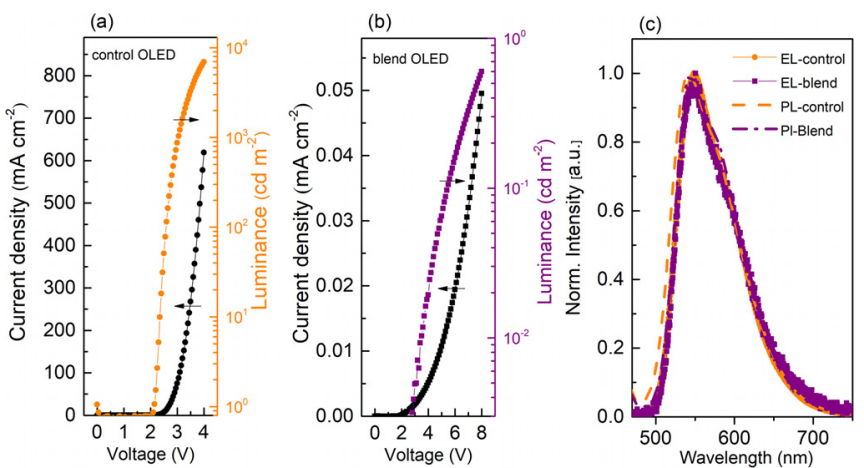

FIG. 5. Current density and luminance curves of control (a) and blend (b) OLED devices. (c) Photoluminescence spectra of control and blend films together with electroluminescence spectra of both OLEDs. 
transport molecule acts as a facilitator of charge transport to the polymer matrix. Together with more efficient injection of holes and blocking of electrons, the blend approach results in enhanced recombination of opposite charges, consequently yielding better optical performances.

See the supplementary material for blend ratio optimization, Xray diffraction spectra, EQE comparison of OLED and hybrid LET devices, and J-V curves of electron/hole only devices.

This project was supported by Aquitaine regional Grant "SMOLED" (No. 2014-1R60306). A. Ablat gratefully acknowledges the financial support of the National Natural Science Foundation of China (Grant Nos. 61604126 and 61464010) and China Scholarship Council (CSC). The authors thank bilateral program (FINE) between France and Japan supported by CNRS and JSPS.

\section{REFERENCES}

${ }^{1}$ A. Hepp, H. Heil, W. Weise, M. Ahles, R. Schmechel, and H. von Seggern, Phys. Rev. Lett. 91, 157406 (2003).

${ }^{2}$ M. Muccini, Nat. Mater. 5, 605 (2006)

${ }^{3}$ S. Z. Bisri, T. Takenobu, and Y. Iwasa, J. Mater. Chem. C 2, 2827 (2014).

${ }^{4}$ S. Z. Bisri, C. Piliego, J. Gao, and M. A. Loi, Adv. Mater. 26, 1176 (2014).

${ }^{5}$ J. Zaumseil, J. Zaumseil, H. Sirringhaus, and H. Sirringhaus, Chem. Rev. 107, 1296 (2007).

${ }^{6}$ A. G. Shulga, S. Kahmann, D. N. Dirin, A. Graf, J. Zaumseil, M. V. Kovalenko, and M. A. Loi, ACS Nano 12, 12805 (2018).

${ }^{7}$ R. Capelli, S. Toffanin, G. Generali, H. Usta, A. Facchetti, and M. Muccini, Nat. Mater. 9, 496 (2010).
${ }^{8}$ S. Schols, C. McClatchey, C. Rolin, D. Bode, J. Genoe, P. Heremans, and A. Facchetti, Adv. Funct. Mater. 18, 3645 (2008).

${ }^{9}$ E. B. Namdas, P. Ledochowitsch, J. D. Yuen, D. Moses, and A. J. Heeger, Appl. Phys. Lett. 92, 183304 (2008).

${ }^{10}$ S. Y. Han, G. S. Herman, and C. H. Chang, J. Am. Chem. Soc. 133, 5166 (2011).

${ }^{11}$ W. Huang, L. Zeng, X. Yu, P. Guo, B. Wang, Q. Ma, R. P. H. Chang, J. Yu, M. J. Bedzyk, T. J. Marks, and A. Facchetti, Adv. Funct. Mater. 26, 6179 (2016).

${ }^{12}$ K. Muhieddine, M. Ullah, B. N. Pal, P. Burn, and E. B. Namdas, Adv. Mater. 26, 6410 (2014).

${ }^{13}$ B. Walker, M. Ullah, G. J. Chae, P. L. Burn, S. Cho, J. Y. Kim, E. B. Namdas, and J. H. Seo, Appl. Phys. Lett. 105, 183302 (2014).

${ }^{14}$ M. Ullah, Y. H. Lin, K. Muhieddine, S. C. Lo, T. D. Anthopoulos, and E. B. Namdas, Adv. Opt. Mater. 4, 231 (2016).

${ }^{15}$ H. Ebata, T. Izawa, E. Miyazaki, K. Takimiya, M. Ikeda, H. Kuwabara, and T. Yui, J. Am. Chem. Soc. 129, 15732 (2007).

${ }^{16}$ K. Takimiya, S. Shinamura, I. Osaka, and E. Miyazaki, Adv. Mater. 23, 4347 (2011).

${ }^{17}$ M. Zambianchi, E. Benvenuti, C. Bettini, C. Zanardi, R. Seeber, D. Gentili, M. Cavallini, M. Muccini, V. Biondo, C. Soldano, G. Generali, S. Toffanin, and M. Melucci, J. Mater. Chem. C 4, 9411 (2016).

${ }^{18}$ J.-H. Kim and J.-W. Park, J. Mater. Chem. C 5, 3097 (2017).

${ }^{19}$ A. Kyndiah, A. Ablat, S. Guyot-Reeb, T. Schultz, F. Zu, N. Koch, P. Amsalem, S. Chiodini, T. Yilmaz Alic, Y. Topal, M. Kus, L. Hirsch, S. Fasquel, and M. Abbas, Sci. Rep. 8, 10946 (2018).

${ }^{20}$ S. Schols, S. Verlaak, C. Rolin, D. Cheyns, J. Genoe, and P. Heremans, Adv. Funct. Mater. 18, 136 (2008).

${ }^{21}$ M. Ullah, A. Armin, K. Tandy, S. D. Yambem, P. L. Burn, P. Meredith, and E. B. Namdas, Sci. Rep. 5, 8818 (2015).

${ }^{22}$ A. Ablat, A. Kyndiah, G. Houin, T. Y. Alic, L. Hirsch, and M. Abbas, Sci. Rep. 9, 6685 (2019).

${ }^{23}$ D. Khim, Y. H. Lin, S. Nam, H. Faber, K. Tetzner, R. Li, Q. Zhang, J. Li, X. Zhang, and T. D. Anthopoulos, Adv. Mater. 29, 1605837 (2017). 